\title{
AIR RAID PRECAUTIONS IN RELATIONSHIP TO THE GENERAL PRACTITIONER.
}

\author{
By W. C. BENTALL, O.B.E., F.R.C.S.E., F.R.G.S. \\ (A.R.P. Staff Officer to the Chief Commissioner of the St. John Ambulance Brigade.)
}

The Editor has asked me to write an article on the above subject, and to emphasise the part that the general practitioner may play after a raid. It is well at the outset to emphasise that the part a doctor may take in dealing with the public after an aerial raid resulting in gas or wound casualties depends entirely on the amount of preparation put in previously to the raid, and the knowledge that he will have to play in a well trained team taking part in all such work. Lack of such knowledge and training would almost inevitably lead to confusion and lack of co-operation, which would to a large extent nullify any of his good intentions It is necessary, therefore, to clarify as far as possible the position of the general practitioner in this matter as laid down by the various instructions already issued, and the work to be done by medical men.

Up to the present time the following is a resume of the plans laid down by the authorities for doctors:-

\section{r.-Courses of Instruction for General Practitioners.}

In 1936 the Home Office appointed and trained several whole time medical men to conduct training classes in certain areas of the country for doctors and nurses. Each of these men had special training for their job and were responsible for medical training in their own immediate areas. The organisation of this scheme was placed under the B.M.A., and classes have been going on ever since. The prime object of these classes was that the medical profession might be cognisant of the value and effectiveness of precautionary measures, and in order that doctors might be able to explain adequately questions which their patients would very naturally put to them as their medical advisers. It was laid down in this course that such instruction did not fit the practitioner to become an instructor of the general public, and it is possible that three reasons account for this $(a)$ the course entered more fully into medical details for the profession than is necessary for the public to be taught; $(b)$ the amount of time in this course given to respirator drill and specialised team work is insufficient for an instructor to possess, and $(c)$ the course being entirely optional a doctor is at perfect liberty to miss any of the lectures if he wishes, and no examination is conducted at the close. Under this organisation murses of training schools were similarly lectured to, and by now practically the whole country has been thus dealt with. The proportion of medical men who thus understand the subject depends entirely on their attendance at this course and their subsequent reading.

\section{2.-Hospitals.}

Many of the larger hospitals have also at the request of the Home Office discussed the part they will play in the scheme, and the work which their doctors, nurses and staff would be expected to undertake. Some of our large hospitals have arranged for various sections of their out-patient departments to deal with first aid treatment of gas and wounds, while others have discussed the preparation of certain wards for the treatment of more specialised cases, such as phosgene poisoning. Doctors on the staffs of large hospitals will make a valuable contribution to the work by making sure that such matters have been brought before the Board of such institutions. 


\section{3.-The Medical Officer of Health's Department.}

It is under this heading that services rendered by general practitioners most definitely fall. The official M.O.H's. have from time to time received memoranda from the Home Office giving explicit instructions as to procedure in all medical matters relating to the preparation of schemes and the after treatment and care of air raid casualties, and all practitioners should be in close liaison with their respective M.O.H. for this purpose. He is the local organising head of medical services, and medical men. Any scheme apart from his knowledge and arrangement is irregular and unrecognised. He is responsible for the organisation of classes, either under his own instructors or by the Grade I instructors of the voluntary organisations of the St. John Ambulance Brigade and the British Red Cross Society (of which there are several thousand throughout the country), and no one but these recognised certificated teachers are eligible for the instruction of the general public. Having secured trained personnel the M.O.H. is responsible for their after training and drafting into Units for service, either in street first aid work, or the treatment of gas and wounded cases in definite fixed first aid posts in the area. He is also generally instructed to co-ordinate local hospitals in his area for more elaborate treatment, and also to select base hospitals remote from populous areas for long or convalescent treatment, the whole to be linked up by an adequate ambulance service. The immensity of his job should be recognised, for in addition to this medical work he is also responsible for medical supervision of water, food, and health conditions in refugee camps after evácuation.

The next question of importance to practitioners is the one of instruction to the public. Since July, I935, when the Home Office started to organise air raid precautions, the emphasis for instructors has gradually changed from that of theoretical instruction in gas warfare to the more practical teaching, training, and drill in the use of precautionary measures and material, so that in twenty hours instruction to members of the public to-day, the various types of respirators occupy a predominating time in the matter of their inspection, wearing, drill, preservation and disinfection, and in the local anti-gas certificate (known as the L.A.G.C.) according to the Home Office Memorandum No. 5 (second edition) issued in May, I938, all details of this latest training is explicitly laid down, and the most important thing concerning general practitioners arising therefrom is, that the instructors for the L.A.G.C. must have either received their 85 per cent. of marks at the examination held at the Government teaching schools at Falfield in Gloucestershire and Easingwold in Yorkshire, or be amongst a certain number of specially qualified teachers whom the Home Office recognise; and the trainees of these classes will be available for appointment under the M.O.H. in the scheme. But instructors to the staffs of large employers may be taught by their trained teachers, doctors and lay-men as laid down in this same Memorandum No. 5 (second edition). All employers of labour throughout the country have been asked by the Home Office to see that their staffs are adequately trained and necessary precautions taken on their premises to deal with air raid dangers. For this purpose many of our doctors are rendering most valuable services.

In addition to actual A.R.P. work itself, many of our doctors will find a large sphere of service in the conduct of the old fashioned "First Aid to Casualty" classes, apart from gas warfare, and this aspect of air raid precautions is rapidly assuming large proportions and a more important place, and only qualified medical 
men are recognised for teaching this subject. Those who hold the first aid certificates of the two voluntary organisations, the St. John Ambulance Brigade and the British Red Cross Society, are the only ones exempt from training.

Two procedures are open to doctors to find out the details of this method of help.-(I) The purchase of the A.R.P. Memorandum No. 5 (second edition) published by His Majesty's Stationery Office and obtainable through all book sellers at the price of $4 \mathrm{~d}$., or (2) to apply personally to the local M.O.H. who has all details of this information in his hands.

It might be helpful to outline post aerial raid procedure, and it may be briefly summarised as follows-

Fixed signs are to be given (a) on the approach of the air raid, $(b)$ when the raiders have passed, and (c) when the infected area has been decontaminated so that people may move about again with safety. Much previous preparation and training are required to make these effective.

For example the casualty clearing parties, the ambulance services and the first aid posts must not only be organised and established, but must have been through a series of practical exercises in imitation of a real raid, these exercises have already proved valuable in finding out weak spots and improving technical measures.

With regard to the first aid casualty clearing parties we must remember the need for familiarity with gas protective clothing, the wearing of steel helmets, respirators, and method of rendering first aid in dangerous cases even with the handicap of the protective clothing. For this party also there must be senior men who may decide which cases may be sent to a casualty clearing hospital because of immediate danger, or to the first aid posts for cleansing and preventing danger which might result to gas infected individuals. It is important to recognise that known war gases need not produce serious or permanent injury if prompt and adequate measures are taken to deal with them. We have in this great scheme "ideal" treatment which is "preventive" so that the symptoms may never develop. The casualties are then despatched to the first aid posts which are allocated throughout the area, city or rural, on plans laid down with due regard to population. At such a first aid post the infected individuals are undressed so that their gassed clothing may not infect themselves and others, passed on to a second room and smeared with a bleaching powder paste to prevent the blistering effect of mustard gas, then washed down with soap and warm water under a shower, and passed on to a third room to be clothed with temporary clothing during the time required for the decontamination of their own clothing which will have been taken away under the supervision of the staff of the M.O.H. to proper decontamination centres, and finally returned to the patients homes. The more serious of these cases will either go on foot or be transported by ambulance to their homes or casualty clearing hospitals. In the casualty clearing hospitals the more seriously effected by choking gas will have to be medically dealt with by oxygen, blood letting, transfusions, etc. (adequate use of a respirator is preventive). Severe wounds, compound fractures and similar injuries that have not been sent direct to the hospital will need accurate diagnosis and treatment. Fortunately with this system few cases affected by mustard gas will come from a first aid post, treatment for this much feared gas is almost entirely one of "first aid." 
The statement of this resumé leaves scope for the medical imagination to fill in innumerable details of treatment. In addition to all this, and at the same time other departments are performing their work, e.g., the air wardens who will be on duty in the streets have practiced their methods of telephonic communication to their centres for the despatch of first aid squads, debris clearing workers, temporary repair of destroyed sewers, water and gas mains or damaged electric supplies. Well trained squadrons will reply to the telephone messages and speedily despatch squads to decontaminate streets and buildings and not until their work is completed is it safe for people to leave their protected rooms or discard their respirators. Many exercises have proven the efficacy of these squads rapidly to cleanse these areas, but it is only by repeated practice in this work that such efficiency is achieved.

A closing word may be said regarding the much discussed respirators. All respirators that are produced by Government, or made by private concerns and passed the Government test, are roo per cent. effective in preventing all known war gases from harming individuals, in spite of the fact there are those who object to the whole scheme making statements to the contrary. Even mustard gas which affects the skin as well only kills by producing pneumonia through the respiratory passages. This killing effect of mustard gas is entirely prevented by the knowledgable application of one of the respirators.

There are three types of respirators to be provided:-

(I) The Service Respirator, which is the heaviest type, consisting of the well-known corrugated tube leading to the filter carried in the haversack on the chest. These are to be issued to those employed for a long time in the gas laden atmosphere and their filters are effective for up to 60 hours.

(2) The Civilian, Duty Respirator, is for those subject to less exposure. These have the filter attached to the facepiece and act for a period of from Io to 20 hours.

(3) The Civilian Respirator. This is the simplest and lightest form which have been produced in their millions, and which the Government scheme definitely arranges for everyone to be in possession of in the case of emergency. They are equally effective with the other two types but their filters are effective for a less period of time, up to 6 or 7 hours. The scheme arranges for these respirators to be in the care of special trained air wardens, part of whose duty will be before raids to fit them to all individuals in the areas where they are responsible, such as a street in a town, or two in a small village, or one for a series of flats in a crowded area, also to collect them immediately after their need for use has passed, and to test the filters and to check off carefully the effectiveness of the respirator as well as to decontaminate and disinfect them for further use. It is interesting to note in this connection that it has been repeatedly stated that the respirators provided gratuitously by our Home Office department in this country are the best that any European country provides and entirely without cost to the patient.

Only those points of this scheme which directly affect the medical practitioner have been dealt with, but it will be seen how much lies behind the whole scheme, and how much depends on practice and co-operative team work. 